\title{
Infectious Disease Reporting and Outbreak Management Improvement Project
}

\author{
Donald E. Brannen*, Melissa Branum and Amy Schmitt
}

Administration, Greene County Public Health, Xenia, $\mathrm{OH}$, USA

Objective

Improve disease reporting and outbreak mangement.

\section{Introduction}

Specific communicable diseases have to be reported by law within a specific time period. In Ohio, prior to 2001, most of these disease

reports were on paper reports that were reported from providers to local health departments. In turn the Communicable Disease Nurse mailed the hardcopies to the Ohio Department of Health (ODH). In 2001 the Ohio Disease Reporting System (ODRS) was rolled out to all local public health agencies in Ohio. ${ }^{1}$ ODRS is Ohio's portion of the National Electronic Disease Surveillance System. ODRS should not be confused with syndromic surveillance systems that are for detecting a disease outbreak before the disease itself is detected. ${ }^{2}$ Chronic disease surveillance system data has been evaluated for long term trends and potential enhancements. ${ }^{3}$ However, the use of communicable disease reports vary greatly. 4 However, the export data has not routinely been used for quality improvement purposes of the disease reporting process itself. In December 2014, Greene County Public Health $(\mathrm{GCPH})$ begain a project to improve reporting of communicable diseases and the response to disease outbreaks.

\section{Methods}

Initial efforts were to understand the current disease reporting process: Quantitative management techniques including creating a logic model and process map of the existing process, brainstorming and ranking of issues. The diseases selected to study included: Campylobacteriosis, Cryptosporidiosis, E. coli O157:H7 \& shiga toxin-producing E. coli, Giardiasis, Influenza-associated hospitalization, Legionnaires' disease, Pertussis, Salmonellosis, and Shigellosis. The next steps included creating a data collection and analysis plan. An updated process map was created and the pre- and post-process maps were compared to identify areas to improve. The median number of days were compared before and after improvements were implemented. Modeling of the impact of the process improvements on the median number of days reported was conducted. Estimation of the impact in healthy number of days derived from the reduction in days to report (if any) were calculated.

\section{Results}

Process improvements identified: Ensure all disease reporters use digital reporting methods preferably starting with electronic laboratory reporting directly to the online disease reporting system, with other methods such as direct web data entry into system, faxing lab reports, or

secure emailing reports, with no or little hard copy mailing; Centralize incoming email and fax reports (eliminating process steps); Standardize backup staffing procedures for disease reporting staff; Formalize incident command procedures under the authorized person in charge for every incident rather than distribute command between environmental and clinical services; and place communicable disease reporting under that single authority rather than clinical services. The days to report diseases were reduced from a median of 2 to .5 days $(\mathrm{p}<.001)$. All the diseases were improved except for crytosporodium due to an outlier report two months late. The estimated societal healthy days saved were valued at $\$ 52,779$ in the first eight months after implementation of the improvements.

\section{Conclusions}

Improvements in disease reporting decreased the reporting time from over 2 days to less than 1 day on average. Estimated societal healthy days saved by this project during the first 9 months was $\$ 52,779$. Management of early command and control for outbreak response was improved.

\section{Keywords}

surveillance; communicable; quality improvement

\section{Acknowledgments}

Matched Funding through Ohio Development Services Agency Grant Control No. SBIG20150570

\section{References}

1. Brannen DE. Ohio Disease Reporting System Rollout. Orientation to individual health departments throughout southwest Ohio to the web based Ohio Disease Reporting System. June 1, 2001 through January $15^{\text {th }}, 2002$.

2. Ottaway, M., Brannen, D. E., Yund. C. B. (2002 Sept 23-24). Practical Evaluation of Electronic Disease Surveillance Systems for Local Public Health. National Syndromic Surveillance Conference, New York, New York. New York Academy of Medicine, NYC Department of Health and Mental Hygiene and the Centers for Disease Control \& Prevention.

3 Brannen, D. E. (2013). Development of a Public Health Surveillance Method to Prevent Melanoma Morbidity. Dissertation, 1-237. ProQuest Publication Number 3591988.

4. Brannen, D. E., Schmitt, A., \& McDonnell, M. (2009 Apr 18). Use of Ohio Disease Reporting System export data by local public health epidemiologists in Ohio. Ohio Academy of Science Annual Meeting Wittenberg University. Abstract and podium presentation.

\section{*Donald E. Brannen}

E-mail: dbrannen@gcph.info 